\title{
IESES E DISSERTACÕES EM ANTROPOLOGIA DEFENDIDAS NA UNIVERIDADE FEDERAL DO RIO GRANDE DO SUL NO PERIOODO DE ABRIL A JULHO DE 2007
}

IESES

\section{FLEISCHER, Soraya}

Orientadora: Claudia Lee W. Fonseca

Parteiras, buchudas e aperreios: uma etnografia do atendimento obstétrico não oficial na cidade de Melgaço, PA.

\section{LEITÃO, Débora Krischke}

Orientadora: Maria Eunice Maciel

Brasil à moda da casa: imagem da nação na moda brasileira contemporânea.

\section{DEVOS, Rafael Victorino}

Orientador: Ruben George Oliven

Questão ambiental sob a ótica da antropologia dos grupos urbanos, nas ithas do Parque Estadual Delta do Jacuí, bairro Arquipélago, Porto Alegre, RS.

\section{BRAGA, Antônio Mendes da Costa}

Orientador: Carlos Alberto Steil

Padre Cícero: sociologia de um padre. Antropologia de um santo. 


\section{ADOMILI, Gianpaolo Knoller}

Orientadora: Cornelia Eckert

Terra e mar, do viver e do trabalhar na pesca marítima. Tempo, espaço e ambiente junto a pescadores de São José do Norte-RS.

\section{VIEIRA, Miriam Steffen}

Orientadora: Claudia Lee W. Fonseca

Universo legal em ato: a construção de categorias jurídicas em torno da violência sexual.

\section{DISSERIACÕES}

\section{RECHENBERG, Fernanda}

Orientadora: Cornelia Eckert

Vamo fala do nosso Lami: estudo antropológico sobre memória coletiva, cotidiano e meio Ambiente no bairro Lami, Porto Alegre.

\section{SILVA, Roberto Antônio Capiotti da}

Orientadora: Cornelia Eckert

Sobre lotes, lares e sonhos: estudo antropológico sobre cotidiano, trajetória social e ação política de moradores da Vila Batista flores em Porto Alegre-RS.

\section{VECCHIO, Maria Carolina}

Orientadora: Claudia Lee W. Fonseca

Onde mora o perigo? Um estudo sobre vidas e práticas de proteção a infância entre moradores de uma vila popular de Porto Alegre". 
SOARES, Maria Andréa dos Santos

Orientadora: Maria Elizabeth Lucas

Na base do muque e da onda: estudo etnográfico de performances entre rappers da Alvo - Associação Cultural da Zona Norte de Porto Alegre. 